\title{
Psychological, social and role functioning as predictors of psychosis in an adolescent psychiatric sample
}

\section{Ärmänen, Anna}

2018-12

Ärmänen , A , Lahti , M , Therman , S , Suvisaari , J \& Lindgren , M 2018 , ' Psychological, social and role functioning as predictors of psychosis in an adolescent psychiatric sample ' , Early Intervention in Psychiatry , vol. 12 , no. 6 , pp. 1064-1071 . https://doi.org/10.1111/eip.12414

http://hdl.handle.net/10138/328158

https://doi.org/10.1111/eip.12414

unspecified

acceptedVersion

Downloaded from Helda, University of Helsinki institutional repository.

This is an electronic reprint of the original article.

This reprint may differ from the original in pagination and typographic detail.

Please cite the original version. 


\section{Early Intervention} IN PSYCHIATRY

\section{Psychological, social, and role functioning as predictors of psychosis in an adolescent psychiatric sample.}

\begin{tabular}{|c|c|}
\hline Journal: & Early Intervention in Psychiatry \\
\hline Manuscript ID & EIP-2016-065.R1 \\
\hline Manuscript Type: & Original Article \\
\hline Date Submitted by the Author: & 05-Sep-2016 \\
\hline Complete List of Authors: & $\begin{array}{l}\text { Ärmänen, Anna; National Institute for Health and Welfare, Department of } \\
\text { Mental Health and Substance Abuse Services; University of Helsinki, The } \\
\text { Institute of Behavioural Sciences } \\
\text { Lahti, Marius; University of Helsinki, Institution of Behavioural Sciences; } \\
\text { University of Edinburgh, British Heart Foundation Centre for Cardiovascular } \\
\text { Science } \\
\text { Therman, Sebastian; National Institute for Health and Welfare, Department } \\
\text { of Mental Health and Substance Abuse Services } \\
\text { Suvisaari, Jaana; National Institute for Health and Welfare, Department of } \\
\text { Mental Health and Substance Abuse Services } \\
\text { Lindgren, Maija; National Institute for Health and Welfare, Department of } \\
\text { Mental Health and Substance Abuse Services }\end{array}$ \\
\hline Keywords: & adolescents, followup studies, functioning, psychosis risk, psychosis \\
\hline
\end{tabular}


Psychological, social, and role functioning as predictors of psychosis in an adolescent psychiatric sample.

\author{
BPsych Anna Ärmänen ${ }^{1,2}$, PhD Marius Lahti ${ }^{2,3}$, PhD Sebastian Therman ${ }^{1}$, Prof Jaana \\ Suvisaari $^{1}$ and PhD Maija Lindgren ${ }^{1}$ \\ ${ }^{1}$ Mental Health Unit, National Institute for Health and Welfare, PO Box 30, 00271, Helsinki, \\ Finland \\ ${ }^{2}$ Institute of Behavioural Sciences, University of Helsinki, PO Box 9, 00014, Helsinki, \\ Finland \\ ${ }^{3}$ The Endocrinology Unit, British Heart Foundation Centre for Cardiovascular Science, \\ Queen's Medical Research Institute, University of Edinburgh, Edinburgh EH16 4TJ, United \\ Kingdom
}

Corresponding author: Miss Anna Ärmänen, National Institute for Health and Welfare, Mental Health Unit, PO Box 30 00271 Helsinki, Finland

Email: anna.armanen@helsinki.fi

$+358407510928$

Acknowledgments

We thank Docent Matti Huttunen for engineering the original study design and the whole Helsinki Prodromal Study group. We also thank all of our participants and our collaborators at the Hospital District of Helsinki and Uusimaa for their effort and for making the study possible. The founding was provided by Academy of Finland Research Programme Strategy Grant (115479) as well as personal grants to Dr Lahti by the Academy of Finland and University of Helsinki Research Funds and to Dr Lindgren by Yrjö Jahnsson Foundation, Alli Paasikivi Foundation, and The Jalmari and Rauha Ahokas Foundation. The funding organizations had no further role in study design, in the collection, analysis and interpretation of data, or in writing of the paper. All authors declare that they have no conflicts of interest. 


\title{
Psychological, social, and role functioning as predictors of psychosis in an adolescent psychiatric sample.
}

\begin{abstract}
Aim: Recent evidence from psychosis-risk studies of preselected samples suggests that early functional impairment may be a vulnerability marker for psychosis. We investigated whether functional impairment predicted later risk of psychotic disorder and psychiatric hospitalizations in adolescents at entry to general psychiatric services.

Methods: 154 adolescents, aged 15-18 years, were recruited to the study at entry to general adolescent psychiatric services in Helsinki, Finland. SIPS and SCID interviews were used to assess psychotic-like symptoms, psychosis risk, and psychiatric diagnoses. Of the adolescents, 46 met the criteria for Clinical High Risk status. The level of functioning was assessed with Global Functioning Social, Role, and Psychological scales. The adolescents were followed for 3-9 (median=5) years via a hospital discharge register. Cox regression analyses were used to examine whether baseline functioning predicted psychotic disorders and psychiatric hospitalizations when controlling for the effect of psychosis risk symptoms.

Results: Impairments in social, role or psychological functioning did not predict psychotic disorders beyond risk symptoms. Impairment in psychological functioning was the only significant predictor of any psychiatric hospitalization after adjusting for positive psychosis-risk symptom severity and level of social and role functioning.
\end{abstract}

Conclusions: Psychosis was predicted by psychotic-like experiences at entry to psychiatric services. No aspect of functioning predicted psychosis in adolescents, which is likely to be explained by the low incidence of psychosis transitions. Severe mental disorders as assessed by psychiatric hospitalizations were predicted by more severe symptomatology as assessed by the psychological functioning scale.

Key words: adolescents, followup studies, functioning, psychosis risk, psychosis 


\section{Introduction}

A psychosis-risk state is characterized by changes in mental state and functioning that are similar to, but do not yet meet the criteria for a psychotic disorder diagnosis ${ }^{1}$. The operationalized definition of clinical high risk (CHR) comprises an attenuated psychotic symptoms syndrome, a brief intermittent psychotic episode syndrome, and a genetic risk with functional deterioration syndrome $\mathrm{e}^{2,3}$. However, the risk of psychosis in individuals fulfilling the criteria for a psychosisrisk state - even in preselected samples - is only about $26 \%$ over a 3 -year follow-up, ${ }^{4,5}$ and the majority of CHR individuals never develop psychosis. Therefore research on additional features that could improve the accuracy of psychosis risk criteria is important.

In individuals with psychosis, a marked impairment in general functioning is present ${ }^{6}$ and the first alterations in functioning can be detected before the disorder onset ${ }^{7}$. A similar functional impairment has also been detected in CHR individuals ${ }^{6}$, among whom a greater impairment in general functioning has been associated with a higher risk of psychosis transition ${ }^{6,8-10}$. In addition, a large subgroup of CHR individuals not transitioning to psychosis often continue to have a marked impairment in functioning ${ }^{11,12}$.

The World Health Organization defines functioning broadly as consisting of bodily functions and several areas of life activities and participation ${ }^{13}$. In psychosis-risk research the focus has been in the areas of social functioning (such as the quantity and quality of relationships and interactions) and role functioning (such as school or work performance) ${ }^{1}$. Functional impairments in both areas have been indicated in both individuals with psychosis and CHR individuals ${ }^{7}$. In CHR studies, impairment in social functioning has predicted transition to psychosis within 1-2 years ${ }^{14-16}$. Even childhood alterations in social functioning have been detected in those transitioning to psychosis in adulthood ${ }^{17,18}$. Role functioning results are less conclusive: impairments have been found in 
CHR individuals ${ }^{7}$, but it is not clear whether they predict psychosis. Findings from the large NAPLS study do not support poor role functioning predicting psychosis $^{14}$, but there are conflicting results from other samples ${ }^{8,19}$. However the measures used for assessing role functioning varied a lot between these studies.

While functional impairments are informative regarding current need for treatment, they may also represent a marker of vulnerability to severe psychopathology. Individuals who later develop psychosis have cognitive impairments early before the disorder onset ${ }^{20}$, and functional impairments associated with psychosis and psychosis risk status have been linked to cognitive impairments $^{21}$. Impairments in functioning are also associated with symptoms. In CHR individuals impairment in social functioning has been associated with a higher level of negative, positive $^{22}$, and disorganized symptoms ${ }^{23}$. Impairment in role functioning has been associated especially with the severity of negative symptoms $s^{22,24}$.

Since previous studies with preselected psychosis risk samples have found early functional impairment to be a significant predictor of psychotic disorders, our aim was to examine whether the same is true in a general adolescent psychiatric sample where adolescents have not sought help specifically for psychosis risk symptoms. We also investigated psychiatric hospitalizations as an additional outcome to determine whether early functional impairment is a more general antecedent for severe mental disorders. Areas of role, social, and psychological functioning were taken into consideration, with a new measure for psychological functioning covering symptom severity and symptom interference with normal functioning. We hypothesized that all functioning areas would be impaired in CHR individuals, but social functioning would be the only predictor of psychosis. In addition, we hypothesized that all areas of functioning would predict all-causes psychiatric hospitalization. 


\section{Methods}

\section{Participants and study protocol}

This study is a part of the Helsinki Prodromal Study, a prospective psychosis-risk study of adolescents in general psychiatric services conducted in Helsinki, Finland ${ }^{25}$. The sample was gathered during the years 2003-2004 and 2007-2008 in public adolescent psychiatric clinics in Helsinki and included all new patients aged 15-18 years. The only exclusion criterion was a psychiatric treatment contact during the past 24 months. 683 patients were screened with the Prodromal Questionnaire $(\mathrm{PQ})^{26}$. After excluding those with a previous psychiatric treatment contact, all adolescents with a minimum of 18 positive symptoms on the $\mathrm{PQ}^{27}(\mathrm{n}=145)$ and a randomized sample of screen-negatives $(n=87)$ were invited to the study. The study procedure is presented in Figure 1.

The final sample consisted of 154 adolescents who completed the baseline measures: Structured Interview for Prodromal Syndromes (SIPS ${ }^{28}$, Structured Clinical Interview for the Diagnostic and Statistical Manual of Mental Disorder for DSM-IV, Clinical version (SCID) ${ }^{29}$, and a large neurocognitive test battery. The research staff, consisting of psychologists, was trained to high standards on the SCID by Professor Jaana Suvisaari and a high inter-rater agreement on SIPS was achieved through a workshop by Rachel Loewy. The participants were followed through the Finnish hospital discharge register (Care Register for Health Care). Hospitalization for psychosis was analysed for those 148 (96\%) adolescents who did not have any previous psychotic disorder at baseline. Any psychiatric hospitalization outcome was analysed for those 133 (86\%) adolescents who did not have any previous psychiatric hospitalization at baseline ${ }^{30}$. 
Parents of the participants were informed about the study and all adolescents gave written informed consent to participate. The study protocol was reviewed and approved by the institutional review boards of the National Institute for Health and Welfare and the Hospital District of Helsinki and Uusimaa. The study was carried out in accordance with the declaration of Helsinki.

\author{
Baseline assessment \\ Information about age, age of treatment onset, age of symptom onset, use of psychiatric \\ medication, GAF and family structure (two-parent nuclear family without any child welfare \\ intervention, yes/no) was gathered from interviews and medical records. Psychosis risk symptoms \\ and psychosis risk status were obtained from the SIPS. A previously found factorial model of the \\ SIPS symptoms in this population was used, dividing the risk symptoms into positive, negative, \\ and general symptoms ${ }^{25}$.
}

Functioning was assessed with Global Functioning scales: Social ${ }^{31}$, Role $^{32}$, and Psychological. The lowest level of functioning during the past month was assessed based on all available data, interviews and medical records on a scale from 1 (extreme dysfunction) to 10 (superior functioning) (see Table 1). Both the social and role scales have been shown to have good construct validity and inter-rater reliability ${ }^{33}$. The psychological functioning scale is an unpublished measure for assessing severity of symptoms and symptom interference with normal functioning, and was created in the NAPLS study ${ }^{34}$ to accompany the role and social functioning scales (Barbara Cornblatt, February $11^{\text {th }}$ 2016, personal communication).

Follow-up assessment 
Information on psychiatric hospital admissions was extracted from the Finnish hospital discharge register from the initial interview until the end of year 2011 resulting in a mean of 5.6 years of follow-up (median=4.5, $\mathrm{SD}=2.25$, range $=2.8-8.9$ years). The main outcomes were hospital treatment for psychotic disorder (ICD-10 codes F20, F22-29, F30.2, F31.2, F31.5, F32.3, or F33.3) and any psychiatric hospital treatment (ICD-10 codes F00-F99, X60-X85, or Y87.0).

\section{Statistical analyses}

Group differences on nominal variables were analysed with Chi-square test and on continuous variables with the Mann-Whitney U test. All analyses were conducted with IBM SPSS Statistics version 21.

Hazard ratios for hospitalization for psychosis $(\mathrm{n}=148)$ and any psychiatric hospitalization $(n=133)$ were assessed in a Cox regression survival analysis. All functioning scales were inverted for these analyses, higher scores thereby indicating lower functioning. First, for both outcomes, each functioning scale was separately entered in a Cox regression model as the sole independent variable. In a previous study of the same population, psychoses were predicted by the SIPS positive symptoms factor, and any psychiatric hospitalizations by psychosis risk status and the SIPS positive and general symptom factors ${ }^{30}$. To investigate hospitalization for psychosis, we therefore included all functioning scales and the SIPS positive symptoms factor as covariates. Similarly, to investigate predictors of any psychiatric hospitalization, the model included all functioning scales, with psychosis risk status, the SIPS positive symptom factor, and the SIPS general symptom factor as covariates. Multicollinearity diagnostics indicated no problems in any of the analyses (all intercorrelations 0.44 or less and all VIF scores 1.5 or less).

\section{Results}




\section{Sample characteristics}

Table 2 presents the demographic and clinical characteristics of the sample at baseline. CHR criteria were met by $46(31 \%)$ participants without previous psychosis. The majority of the adolescents entering psychiatric health care had at least one mental disorder diagnosis at baseline, the most common diagnoses being mood disorders (75\%) and anxiety disorders (32\%). Psychiatric medication and positive status on the PQ screen were more common among CHR adolescents than non-CHR adolescents. The most common psychiatric medications prescribed were antidepressants to 47 individuals, sedative-hypnotic medications to 16 individuals, and antipsychotics to 14 individuals. Positive, negative, disorganized and general symptoms were more common among CHR adolescents than non-CHR adolescents.

\section{Functioning of adolescents at entry to mental health services}

The mean score for social functioning was $7.0(\mathrm{SD}=1.2$, median=7, range $=3-9)$, for role functioning $6.6(\mathrm{SD}=1.4$, median=7, range $=3-9)$ and for psychological functioning $6.0(\mathrm{SD}=0.9$, median $=6$, range $=3-8$ ). The levels of social, role, and psychological functioning were significantly lower in CHR adolescents (see Table 3). Impairment in psychological functioning was also associated with use of psychiatric medication and a positive PQ screening result. Role functioning was significantly lower for those not living in a two-parent nuclear family. Psychiatric hospitalization for psychosis or any psychiatric hospitalization were not associated with social or role functioning, but any psychiatric hospitalization was associated with lower psychological functioning.

\section{Predictors of hospitalization for psychosis}

Seven (5\%) psychosis transitions occurred during the follow-up. The mean interval between time of inclusion and hospital treatment for psychotic disorder was 275 days $(\mathrm{SD}=258$, median=234, 
range $=13-671$ days). None of the functioning scales predicted transition to psychosis (Table 4, separate models). In a model including all functioning scales and the SIPS positive symptom factor, positive symptoms remained as the only predictor of increased risk of psychosis (Table 4, model 1).

\section{Predictors of any psychiatric hospitalization}

Of the 133 participants with no previous psychiatric hospitalizations $26(20 \%)$ were hospitalized during the follow-up and the mean time between inclusion and hospital admission was 514 days $(\mathrm{SD}=527$, median $=349$, range $=12-2226$ days $)$. Analysed separately, poor psychological functioning predicted a higher risk of psychiatric hospitalizations while the other functioning scales did not show significant effects (Table 5, separate models). When combining all functioning scales, CHR status and SIPS positive and general symptom factors, psychological functioning remained as the only significant predictor of psychiatric hospitalizations (Table 5, model 1).

\section{Discussion}

The aim of our longitudinal study was to examine whether the previous findings of an association between early functional impairment and later transition to psychosis replicate in a general adolescent psychiatric sample. Even though social, role, and psychological functioning were more impaired in CHR individuals, these were not significant predictors of transition to psychosis. A higher intensity of positive symptoms remained as the only predictor of psychosis transition in a multivariate model. This association between early positive symptoms and later transition to psychosis has been widely established in previous birth cohort studies ${ }^{35-38}$ as well as in the majority of clinical psychosis-risk studies ${ }^{8,9,14}$. 
Functional impairments overall were less severe in our sample than in previous studies: on average the functioning of adolescents at entry to psychiatric services was only mildly impaired. The less severe impairment in functioning may be related to the lower age of the individuals in the current sample compared to previous research. It may also reflect the easy access to adolescent mental services: early detection and treatment of adolescent mental difficulties has been the first priority in developing adolescent psychiatric services in Finland ${ }^{39}$. Finland is one of the few countries where adolescent psychiatry is an independent medical specialty, and a national strategy for specialized adolescent psychiatric services was published already in $1987^{39}$. Public health services are financed by local authorities, and outpatient psychiatric services are free for all patients $^{39}$. However, even though the public strategy has facilitated access to treatment, the gap between the onset of symptoms and onset of treatment is still approximately one year, reflecting a delay in treatment seeking.

Impairment in social functioning did not predict transition to psychosis as in previous studies with CHR adolescents ${ }^{14,15}$. This is likely to be attributable to the less selective and less impaired sample in the current study, including treatment-seeking adolescents both at psychosis risk and not at psychosis risk. In addition, in the current sample the adolescents sought treatment from general psychiatric services whereas in previous studies the participants have sought help specifically for psychotic-like symptoms and the referring clinician's impression of possible psychosis risk may often have been important. Therefore the transition rate to psychosis in the current sample remained low compared to previous studies. However it should be noted that impairment in social functioning has been associated with psychosis in a few birth cohort studies as well ${ }^{17}$.

Our aim was also to investigate whether functional impairment in treatment-seeking adolescents predicted severe psychopathology in general. Psychosis in not the only relevant outcome since it 
can be seen as a somewhat arbitrary agreement on certain criteria and includes only a restricted number of symptoms ${ }^{40}$. Thus, we used all psychiatric hospitalizations as an additional outcome to capture less specific severe symptoms, functional impairment, and poor prognosis. This outcome was also more common in our sample, giving the analysis better statistical power.

We found that poorer psychological functioning was the only significant predictor of psychiatric hospitalizations. The psychological functioning scale is a new unpublished measure that assesses the severity of symptoms as well as the level of symptom interference with normal functioning. As this simple measure was able to predict hospitalizations, it might be a valuable addition to the assessment of functioning in clinical high-risk studies. Early severe symptoms predicting later severe mental health outcomes is in accordance with the existing evidence of a symptomatic prodrome preceding severe mental disorders ${ }^{1,41-43}$ and research on the continuity of severe symptomatology from early adolescence to adulthood ${ }^{44-46}$. However, it should be noted that there is little research using psychiatric hospitalization itself as an outcome measure.

The strengths of the current study include the prospective study design with follow-up up to nine years allowing calculation of predictive power. The global functioning scales provided information on separate functioning domains in age-appropriate measures designed specifically for psychosis risk assessments, although the scale for psychological functioning has not been previously used in research or validated. The current sample was not pre-selected in psychosis risk allowing greater generalizability of the results. At the same time, psychoses were rare in this general psychiatric sample, and the small number of transitions limited the statistical power and the reliability in psychosis prediction analyses. The SIPS and SCID interviews as well as global functioning scales: role and social are commonly used and show good psychometric 
properties $^{28,33,47}$. The hospital discharge register as the outcome measure is considered a reliable, valid, and conservative measure for mental disorders ${ }^{48}$.

In the present study, we found that severe psychiatric outcomes are predicted by severe positive symptoms at early stage. We did not find impairment in functioning to predict psychosis, which is likely to be attributable to the low rate of psychosis transitions in this sample, which restricted statistical power. In the future, it would be important to replicate the results concerning early functioning in another independent general psychiatric sample.

\section{References}

1. Addington J, Heinssen R. Prediction and Prevention of Psychosis in Youth at Clinical High Risk. Annu Rev Clin Psychol. 2012;8:269-289. doi:10.1146/annurev-clinpsy032511-143146.

2. Yung AR, McGorry PD. The prodromal phase of first-episode psychosis: Past and current conceptualizations. Schizophr Bull. 1996;22(2):353-370. doi:10.1093/schbul/22.2.353.

3. Fusar-Poli P, Borgwardt A, Bechdolf A, et al. The Psychosis High-Risk State: A Comprehensive State-of-the-Art Review. JAMA Psychiatry. 2013;70(1):107-120. doi:10.1001/jamapsychiatry.2013.269.

4. Fusar-Poli P, Cappucciati M, Rutigliano G, et al. At risk or not at risk? A metaanalysis of the prognostic accuracy of psychometric interviews for psychosis prediction. World Psychiatry. 2015;14:322-332. doi:10.1002/wps.20250.

5. Schultze-Lutter F, Michel C, Schmidt SJ, et al. EPA guidance on the early detection of clinical high risk states of psychoses. Eur Psychiatry. 2015;30:405-416. doi:10.1016/j.eurpsy.2015.01.010. 
6. Fusar-Poli P, Rocchetti M, Sardella A, et al. Disorder, not just state of risk: Metaanalysis of functioning and quality of life in people at high risk of psychosis. $\mathrm{Br} J$ Psychiatry. 2015;207:198-206. doi:10.1192/bjp.bp.114.157115.

7. Addington J, Penn D, Woods SW, Addington D, Perkins DO. Social functioning in individuals at clinical high risk for psychosis. Schizophr Res. 2008;99(1-3):119-124. doi:10.1016/j.schres.2007.10.001.

8. Ruhrmann S, Schultze-Lutter F, Salokangas RKR, et al. Prediction of Psychosis in Adolescents and Young Adults at High Risk. Arch Gen Psychiatry. 2010;67(3):241251. doi:10.1001/archgenpsychiatry.2009.206.

9. Thompson A, Nelson B, Yung AR. Predictive validity of clinical variables in the "at risk" for psychosis population: International comparison with results from the North American Prodrome Longitudinal Study. Schizophr Res. 2011;126:51-57. doi:10.1016/j.schres.2010.09.024.

10. Nelson B, Yuen HP, Wood SJ, et al. Long-term Follow-up of a Group at Ultra High Risk (“Prodromal”) for Psychosis. JAMA Psychiatry. 2013;70(8):793-802. doi:10.1001/jamapsychiatry.2013.1270.

11. Lin A, Wood SJ, Nelson B, et al. Neurocognitive predictors of functional outcome two to 13 years after identification as ultra-high risk for psychosis. Schizophr Res. 2011;132(1):1-7. doi:10.1016/j.schres.2011.06.014.

12. Addington J, Cornblatt BA, Cadenhead KS, et al. At clinical high risk for psychosis: outcome for nonconverters. Am J Psychiatry. 2011;168(8):800-805. doi:10.1176/appi.ajp.2011.10081191.

13. World Health Organization. Internation Classification of Functioning, Disability and Health. Geneva: World Health Organization; 2001.

14. Cannon TD, Cadenhead K, Cornblatt B, Woods SW. Prediction of Psychosis in Youth 
at High Clinical Risk. Arch Gen Psychiatry. 2008;65(1):28-37.

15. Schlosser DA, Jacobson S, Chen Q, et al. Recovery from an at-risk state: clinical and functional outcomes of putatively prodromal youth who do not develop psychosis. Schizophr Bull. 2012;38(6):1225-1233. doi:10.1093/schbul/sbr098.

16. Velthorst E, Nieman DH, Linszen D, et al. Disability in people clinically at high risk of psychosis. Br J Psychiatry. 2010;197(4):278-284. doi:10.1192/bjp.bp.109.075036.

17. Welham J, Isohanni M, Jones P, McGrath J. The antecedents of Schizophrenia: A review of birth cohort studies. Schizophr Bull. 2009;35(3):603-623. doi:10.1093/schbul/sbn084.

18. Tarbox SI, Pogue-Geile MF. Development of social functioning in preschizophrenia children and adolescents: a systematic review. Psychol Bull. 2008;34(4):561-583. doi:10.1037/0033-2909.34.4.561.

19. Fusar-Poli P, Byrne M, Valmaggia L, et al. Social dysfunction predicts two years clinical outcome in people at ultra high risk for psychosis. $J$ Psychiatr Res. 2010;44:294-301. doi:10.1016/j.jpsychires.2009.08.016.

20. Woodberry KA, Giuliano AJ, Seidman LJ. Premorbid IQ in schizophrenia: A metaanalytic review. Am J Psychiatry. 2008;165(5):579-587. doi:10.1176/appi.ajp.2008.07081242.

21. Cotter J, Drake RJ, Bucci S, Firth J, Edge D, Yung AR. What drives poor functioning in the at-risk mental state? A systematic review. Schizophr Res. 2014;159:267-277. doi:10.1016/j.schres.2014.09.012.

22. Wilson C, Kline E, Thompson E, et al. Comparison of measures of functioning for use with treatment-seeking adolescents experiencing attenuated symptoms of psychosis. Early Interv Psychiatry. 2016;10:81-87. doi:10.1111/eip.12189.

23. Carrión RE, McLaughlin D, Goldberg TE, et al. Prediction of functional outcome in 
individuals at clinical high risk for psychosis. JAMA psychiatry. 2013;70(11):11331142. doi:10.1001/jamapsychiatry.2013.1909.

24. Meyer EC, Carrión RE, Cornblatt BA, et al. The relationship of neurocognition and negative symptoms to social and role functioning over time in individuals at clinical high risk in the first phase of the North American Prodrome Longitudinal Study. Schizophr Bull. 2014;40(6):1452-1461. doi:10.1093/schbul/sbt235.

25. Lindgren M, Manninen M, Laajasalo T, et al. The relationship between psychotic-like symptoms and neurocognitive performance in a general adolescent psychiatric sample. Schizophr Res. 2010;123:77-85. doi:10.1016/j.schres.2010.07.025.

26. Loewy RL, Bearden CE, Johnson JK, Raine A, Cannon TD. The Prodromal Questionnaire (PQ): Preliminary validation of a self-report screening measure for prodromal and psychotic syndromes. Schizophr Res. 2005;1:117-125.

27. Loewy RL, Therman S, Manninen M, Huttunen MO, Cannon TD. Prodromal psychosis screening in adolescent psychiatry clinics. Early Interv Psychiatry. 2012;6(1):69-75. doi:10.1111/j.1751-7893.2011.00286.x.

28. Miller TJ, McGlashan TH, Rosen JL, et al. Prospective diagnosis of the initial prodrome for schizophrenia based on the structured interview for prodromal syndromes: Preliminary evidence of interrater reliability and predictive validity. Am J Psychiatry. 2002;159:863-865. doi:10.1176/appi.ajp.159.5.863.

29. First MB, Spitzer RL, Gibbon M, Williams JBW. Stuctured clinical interview for DSM-IV axis I disorders, clinical version (SCID-CV). 1996; Washington.

30. Lindgren M, Manninen M, Kalska H, et al. Predicting psychosis in a general adolescent psychiatric sample. Schizophr Res. 2014;158:1-6. doi:10.1016/j.schres.2014.06.028.

31. Auther AM, Smith CW, Cornblatt BA. Global Functioning: Social Scale (GF: Social). 
2006;Glen Oaks,

32. Niendam TA, Bearden CE, Johnson JK, Cannon TD. Global Functioning: Role Scale (GF: Role). 2006;Los Angele.

33. Cornblatt BA, Auther AM, Niendam T, et al. Preliminary findings for two new measures of social and role functioning in the prodromal phase of schizophrenia. Schizophr Bull. 2007;33(3):688-702. doi:10.1093/schbul/sbm029.

34. Addington J, Cadenhead KS, Cannon TD, et al. North American Prodrome Longitudinal Study: A Collaborative Multisite Approach to Prodromal Schizophrenia Research. Schizophr Bull. 2007;33(3):665-672. doi:10.1093/schbul/sbl075.

35. Welham J, Scott J, Williams G, et al. Emotional and behavioural antecedents of young adults who screen positive for non-affective psychosis: a 21-year birth cohort study. Psychol Med. 2009;39(4):625-634. doi:10.1017/S0033291708003760.

36. Poulton R, Caspi A, Moffitt TE, Cannon M, Murray R, Harrington H. Children's SelfReported Psychotic Symptoms and Adult Schizophreniform Disorder. Arch Gen Psychiatry. 2000;57:1053-1058. doi:10.1001/archpsyc.57.11.1053.

37. Fisher HL, Caspi A, Poulton R, et al. Specificity of childhood psychotic symptoms for predicting schizophrenia by 38 years of age: a birth cohort study. Psychol Med. 2013;43(10):2077-2086. doi:10.1017/S0033291712003091.

38. Zammit S, Kounali D, Cannon M, et al. Psychotic experiences and psychotic disorders at age 18 in relation to psychotic experiences at age 12 in a longitudinal populationbased cohort study. Am J Psychiatry. 2013;170(7):742-750. doi:10.1176/appi.ajp.2013.12060768.

39. Laukkanen E, Pylkkänen K, Hartikainen B, Luotoniemi M, Julma K, Aalberg VA. A new priority in psychiatry: focused services for adolescents. 2003:(1):37-43.

40. Yung AR, Nelson B, Thompson A, Wood SJ. The psychosis threshold in Ultra High 
Risk (prodromal) research: is it valid? Schizophr Res. 2010;120:1-6. doi:10.1016/j.schres.2010.03.014.

41. Werbeloff N, Drukker M, Dohrenwend BP, et al. Self-reported Attenuated Psychotic Symptoms as Forerunners of Severe Mental Disorders Later in Life. Arch Gen Psychiatry. 2012;69(5):467-475. doi:10.1001/archgenpsychiatry.2011.1580.

42. Jackson A, Cavanagh J, Scott J. A systematic review of manic and depressive prodromes. $J$ Affect Disord. 2003;74:209-217. doi:10.1016/S0165-0327(02)00266-5.

43. Skjelstad DV, Malt UF, Holte A. Symptoms and signs of the initial prodrome of bipolar disorder. A systematic review. J Affect Disord. 2010;126:1-13. doi:10.1016/j.jad.2009.10.003.

44. Copeland WE, Shanahan L, Costello EJ, Angold A. Childhood and adolescent psychiatric disorders as predictors of young adult disorders. Arch Gen Psychiatry. 2009;66(7):764-772. doi:10.1001/archgenpsychiatry.2009.85.

45. Copeland WE, Adair CE, Smetanin P, et al. Diagnostic transitions from childhood to adolescence to early adulthood. J Child Psychol Psychiatry. 2013;54(7):791-799. doi:10.1111/jcpp. 12062 .

46. Kessler RC, Amminger GP, Aguilar-Gaxiola S, Alonso J, Lee S, Ustün TB. Age of onset of mental disorders: a review of recent literature. Curr Opin Psychiatry. 2007;20(4):359-364. doi:10.1097/YCO.0b013e32816ebc8c.

47. Miller TJ, McGlashan TH, Rosen JL, et al. Prodromal assessment with the structured interview for prodromal syndromes and the scale of prodromal symptoms: predictive validity, interrater reliability, and training to reliability. Schizophr Bull. 2003;29(4):703-715. doi:10.1093/oxfordjournals.schbul.a007040.

48. Sund R. Quality of the Finnish Hospital Discharge Register: A systematic review. Scand J Public Health. 2012;40:505-515. doi:10.1177/1403494812456637. 
Table 1. Levels of functioning in Global functioning scales.

Table 2. Demographic and clinical characteristics at baseline, including both SIPS symptom sum scores and SIPS symptom factor scores.

\begin{tabular}{|c|c|c|c|c|}
\hline & $\begin{array}{c}\text { Total, } n=148 \\
\text { Frequency }(\%) \text { or } \\
\text { mean }(\mathrm{SD}), \text { range }\end{array}$ & $\begin{array}{c}\text { CHR, } n=46 \\
\text { Frequency }(\%) \text { or } \\
\text { mean }(\mathrm{SD}), \text { range }\end{array}$ & $\begin{array}{l}\text { Non-CHR, } n=102 \\
\text { Frequency }(\%) \text { or } \\
\text { mean }(\mathrm{SD}), \text { range }\end{array}$ & $\begin{array}{c}\text { Group } \\
\text { difference } \\
\mathrm{p}\end{array}$ \\
\hline Female & $118(80 \%)$ & $39(85 \%)$ & $79(78 \%)$ & .30 \\
\hline Age & $16.6(0.9), 15-18$ & $16.6(0.8), 15-18$ & $16.6(0.9), 15-18$ & .56 \\
\hline $\begin{array}{l}\text { Two-parent nuclear } \\
\text { family }\end{array}$ & $64(43 \%)$ & $17(37 \%)$ & $47(46 \%)$ & .30 \\
\hline Age of symptom onset & $14.1(2.3), 7-18$ & $13.9(2.4), 7-17$ & $14.2(2.3), 7-18$ & .47 \\
\hline Age of treatment onset & $15.3(2.1), 7-18$ & $14.9(2.4), 7-18$ & $15.4(1.9), 7-18$ & .34 \\
\hline $\begin{array}{l}\text { Any psychiatric } \\
\text { medication }\end{array}$ & $58(39 \%)$ & $25(54 \%)$ & $33(32 \%)$ & .01 \\
\hline PQ screen positive & $101(68 \%)$ & $39(85 \%)$ & $62(61 \%)$ & .004 \\
\hline GAF & $48.4(13.1), 10-80$ & $40.2(10.9), 10-58$ & $50.1(12.4), 18-80$ & $<.001$ \\
\hline $\begin{array}{l}\text { SIPS positive } \\
\text { symptoms (P1-P5) }\end{array}$ & $6.7(4.5), 0-20$ & $11.3(3.0), 3-20$ & $4.6(3.4), 0-15$ & $<.001$ \\
\hline $\begin{array}{l}\text { SIPS negative } \\
\text { symptoms (N1-N6) }\end{array}$ & $10.5(5.8), 0-29$ & $14.5(5.7), 4-29$ & $8.6(4.8), 0-22$ & $<.001$ \\
\hline $\begin{array}{l}\text { SIPS disorganized } \\
\text { symptoms (D1-D4) }\end{array}$ & $4.6(2.8), 0-12$ & $6.3(2.7), 2-12$ & $3.8(2.5), 0-12$ & $<.001$ \\
\hline $\begin{array}{l}\text { SIPS general } \\
\text { symptoms (G1-G4) }\end{array}$ & $8.9(3.9), 0-17$ & $11.1(3.4), 4-17$ & $8.0(3.7), 0-14$ & $<.001$ \\
\hline $\begin{array}{l}\text { SIPS positive } \\
\text { symptom factor }\end{array}$ & $0.05(0.9),-1.6-2.2$ & $0.8(0.8),-1.4-2.2$ & $-0.3(0.8),-1.6-1.9$ & $<.001$ \\
\hline
\end{tabular}


1

2

3

4

5

6

7

8

9

10

11

12

13

14

15

16

17

18

19

20

21

22

23

24

25

26

27

28

29

30

31

32

33

34

35

36

37

38

39

40

41

42

43

44

45

46

47

48

49

50

51

52

53

54

55

56

57

58

59

60
SIPS negative symptom factor

SIPS general symptom factor

$\mathrm{P}$ values represent the test results of Chi-square test for nominal variables and Mann-Whitney U test for continuous variables.

Group differences with $\mathrm{p} \leq .05$ are marked in bold.

GAF refers to Global Assessment of Functioning score. 
Table 3. Associations between functioning, demographic characteristics and psychiatric outcome.

\begin{tabular}{|c|c|c|c|c|c|c|c|c|c|c|c|c|c|c|}
\hline & & \multicolumn{5}{|c|}{$\underline{\text { Social functioning }}$} & \multicolumn{4}{|c|}{$\underline{\text { Role functioning }}$} & \multicolumn{4}{|c|}{$\begin{array}{l}\text { Psychological } \\
\text { functioning }\end{array}$} \\
\hline & & $\mathrm{n}$ & mean & $\mathrm{SD}$ & $\mathrm{U}$ & $\mathrm{p}$ & mean & $\mathrm{SD}$ & $\mathrm{U}$ & $\mathrm{p}$ & mean & $\mathrm{SD}$ & $\mathrm{U}$ & $\mathrm{p}$ \\
\hline \multirow[t]{2}{*}{ Gender } & Female & 118 & 7.1 & 1.0 & 1736.5 & 0.87 & 6.6 & 1.3 & 1654.5 & 0.57 & 5.9 & 0.9 & 1485.0 & 0.15 \\
\hline & Male & 30 & 6.9 & 1.7 & & & 6.7 & 1.5 & & & 6.2 & 1.0 & & \\
\hline \multirow[t]{2}{*}{ PQ-status } & Positive & 101 & 7.0 & 1.0 & 2181.5 & 0.41 & 6.7 & 1.3 & 2413.5 & 0.87 & 5.8 & 0.8 & 1863.0 & 0.03 \\
\hline & Negative & 47 & 7.1 & 1.4 & & & 6.6 & 1.5 & & & 6.2 & 1.1 & & \\
\hline \multirow[t]{2}{*}{$\begin{array}{l}\text { Family } \\
\text { structure }\end{array}$} & $\begin{array}{l}\text { Two- } \\
\text { parent } \\
\text { nuclear } \\
\text { family }\end{array}$ & 64 & 6.8 & 1.2 & 2226.0 & 0.06 & 6.9 & 1.3 & 3247.5 & 0.03 & 5.9 & 1.0 & 2622.0 & 0.79 \\
\hline & Other & 84 & 7.2 & 1.1 & & & 6.4 & 1.4 & & & 6.0 & 0.9 & & \\
\hline \multirow[t]{2}{*}{ Medication } & Yes & 58 & 7.0 & 1.3 & 2566.0 & 0.86 & 6.5 & 1.6 & 2728.5 & 0.63 & 5.7 & 0.9 & 3294.0 & 0.005 \\
\hline & No & 90 & 7.1 & 1.1 & & & 6.7 & 1.2 & & & 6.1 & 0.9 & & \\
\hline \multirow{2}{*}{$\begin{array}{l}\text { Psychosis risk } \\
\text { status }\end{array}$} & CHR & 46 & 6.5 & 1.4 & 1618.5 & 0.002 & 6.3 & 1.3 & 1894.0 & 0.05 & 5.6 & 0.8 & 1600.0 & 0.001 \\
\hline & Non-CHR & 102 & 7.3 & 1.0 & & & 6.8 & 1.4 & & & 6.1 & 1.0 & & \\
\hline \multirow{2}{*}{$\begin{array}{l}\text { Psychosis at } \\
\text { follow-up }\end{array}$} & Yes & 7 & 6.7 & 1.6 & 462.0 & 0.77 & 6.3 & 1.4 & 419.5 & 0.49 & 5.4 & 1.1 & 355.0 & 0.19 \\
\hline & No & 141 & 7.1 & 1.2 & & & 6.6 & 1.4 & & & 6.0 & 0.9 & & \\
\hline Psychiatric & Yes & 26 & 7.0 & 1.2 & 1336.5 & 0.75 & 6.5 & 1.4 & 1310.0 & 0.64 & 5.6 & 0.9 & 967.0 & 0.01 \\
\hline $\begin{array}{l}\text { hospitalization } \\
\text { at follow-up }\end{array}$ & No & 107 & 7.1 & 1.2 & & & 6.7 & 1.3 & & & 6.2 & 0.8 & & \\
\hline
\end{tabular}

Mann-Whitney U test.

Group differences with $\mathrm{p} \leq .05$ are marked in bold. 
Table 4. Cox regression models predicting psychosis.

\begin{tabular}{lrrrr}
\hline & $\begin{array}{c}\text { Social } \\
\text { functioning }\end{array}$ & $\begin{array}{c}\text { Role } \\
\text { functioning }\end{array}$ & $\begin{array}{c}\text { Psychological } \\
\text { functioning }\end{array}$ & $\begin{array}{c}\text { SIPS positive } \\
\text { symptom factor }\end{array}$ \\
\hline Separate models & 1.24 & 1.20 & 1.76 & \\
$\quad$ HR & $0.70-2.19$ & $0.71-2.01$ & $0.85-3.67$ & \\
95\% CI for HR & 0.46 & 0.50 & 0.13 & \\
p & & & & $\mathbf{2 . 7 3}$ \\
Model 1 & 0.80 & 1.08 & 1.65 & $\mathbf{1 . 0 9 - 6 . 8 3}$ \\
HR & $0.39-1.67$ & $0.61-1.91$ & $0.67-4.08$ & $\mathbf{0 . 0 3}$ \\
95\% CI for HR & 0.56 & 0.79 & 0.28 & \\
p &
\end{tabular}

Separate models represent the results of each functioning scale separately analysed.

Model 1 includes all functioning scales and SIPS positive symptom factor as covariates.

$\mathrm{HR}=$ Hazard ratio reflecting the change in hazard of transition to psychosis for every additional increase in predictor variables.

$95 \% \mathrm{CI}=95 \%$ confidence interval. $\mathrm{P} \leq .05$ are marked in bold.

Table 5. Cox regression models predicting psychiatric hospitalization.

\begin{tabular}{lrrrrrr}
\hline & $\begin{array}{c}\text { Social } \\
\text { functioning }\end{array}$ & $\begin{array}{c}\text { Role } \\
\text { functioning }\end{array}$ & $\begin{array}{c}\text { Psychological } \\
\text { functioning }\end{array}$ & $\begin{array}{c}\text { SIPS } \\
\text { positive } \\
\text { symptom } \\
\text { factor }\end{array}$ & $\begin{array}{c}\text { SIPS } \\
\text { general } \\
\text { symptom } \\
\text { factor }\end{array}$ & $\begin{array}{c}\text { CHR } \\
\text { status }\end{array}$ \\
\hline Separate models & & & & & & \\
$\quad$ HR & 1.10 & 1.07 & $\mathbf{1 . 9 5}$ & & & \\
95\% CI for HR & $0.79-1.52$ & $0.80-1.42$ & $\mathbf{1 . 2 4 - 3 . 0 7}$ & & & \\
p & 0.58 & 0.65 & $\mathbf{0 . 0 0 4}$ & & & \\
Model 1 & & & & & & \\
HR & 0.86 & 0.90 & $\mathbf{1 . 9 1}$ & 1.34 & 1.79 & 0.79 \\
95\% CI for HR & $0.58-1.28$ & $0.66-1.24$ & $\mathbf{1 . 1 1 - 3 . 2 8}$ & $0.77-2.33$ & $0.91-3.52$ & $0.26-2.37$ \\
p & 0.45 & 0.53 & $\mathbf{0 . 0 2}$ & 0.30 & 0.09 & 0.68 \\
\hline
\end{tabular}

Separate models represent the results of each functioning scale separately analysed.

Model 1 includes all functioning scales and CHR status, SIPS positive and SIPS gene symptoms factors as covariates. $\mathrm{HR}=$ Hazard ratio reflecting the change in hazard of psychiatric hospitalization for every additional increase in predictor variables. $95 \% \mathrm{CI}=95 \%$ confidence interval. $\mathrm{P} \leq .05$ are marked in bold. 
Figure 1. Study procedure. 


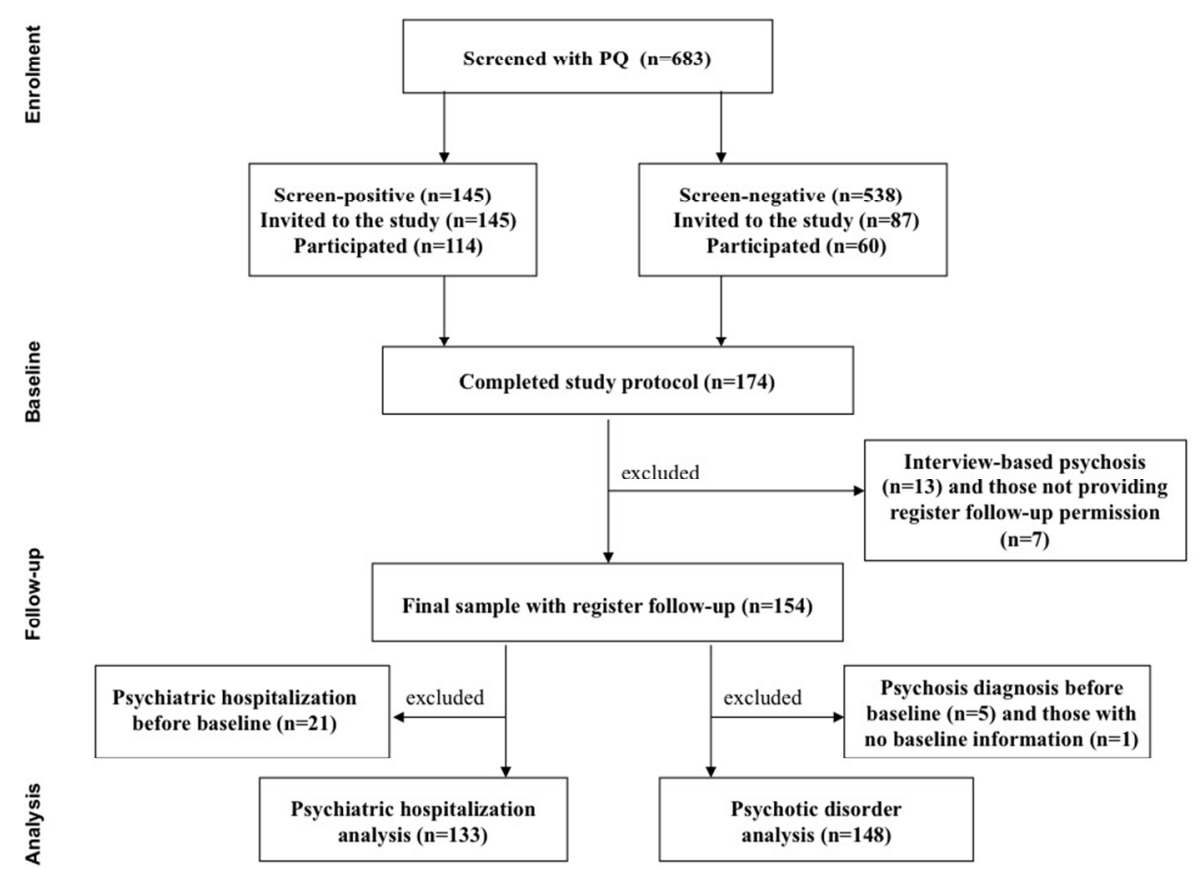

Figure 1 . Study procedure.

$377 \times 283 \mathrm{~mm}(72 \times 72$ DPI $)$ 